\title{
Pengaruh Stack Berpori Acak Bahan Alami, Sintesis dan Logam pada Sistem Pendingin Termoakustik
}

\author{
Qonitatul Hidayah*, Putih Asmara, Mega C. Gupita, Ikhsan Setiawan and Agung Bambang Setio Utomo
}

\begin{abstract}
Ringkasan
Telah dilakukan penelitian mengenai pengaruh stack berpori acak bahan alami (gambas), sintetis (dacron), dan kasa logam (mesh) serta diberi penukar kalor tambahan yang dialiri air. Adapun Resonator yang digunakan berbentuk silinder dengan satu ujung tertutup, sedangkan ujung terbukanya dihubungkan dengan loudspeaker yang menyediakan gelombang bunyi (sistem standing wave). Hasil yang diperoleh adalah bahwa telah terjadi perubahan suhu pada tandon di kiri - kanan stack gambas (bahan alami), dakron (sintetis) atau mesh kasa (logam) yang kemudian disebut tandon panas dan dingin. Penurunan suhu tandon dingin terbesar menggunakan jenis stack gambas $(6 \mathrm{~cm})$ dengan penurunan suhu sebesar $(11,3 \pm 0,1)^{\circ} \mathrm{C}$, stack dakron $(8 \mathrm{~cm})$ sebesar $(13,6 \pm 0,1)^{\circ} \mathrm{C}$, dan stack mesh logam sebesar $(6,1 \pm 0,1)^{\circ} \mathrm{C}$. Bahkan menggunakan sistem gelombang berjalan, penurunan suhu dapat mencapai $21,5^{\circ} \mathrm{C}$ (dari $26,5^{\circ} \mathrm{C}$ menjadi $5,1^{\circ} \mathrm{C}$ ). Dengan demikian telah terwujud sebuah pendingin termoakustik menggunakan stack gambas, dacron dan mesh logam serta penukar kalor tambahan yang dialiri air dalam rangka meningkatkan kinerja sistem.
\end{abstract}

Kata Kunci : termoakustik, gelombang berdiri, bahan organik, sintesis, logam.

\section{Abstract}

Research on the effects of random porous, synthetic (dacron), and metal mesh (mesh) random porous stacks has been carried out as well as given an additional heat exchanger flowing with water. The resonator used is cylindrical with one closed end, while the open end is connected to a loudspeaker that provides sound waves (standing wave system). The results obtained are that there has been a change in temperature in the reservoir to the left and right of the gambas stack (natural material), dacron (synthetic) or mesh mesh (metal) which is then called a hot and cold reservoir. The biggest decrease in temperature of the cold reservoir uses the type of gambas stack $(6 \mathrm{~cm})$ with a decrease in temperature of $(11.3 \pm 0.1)^{\circ} \mathrm{C}$, dacron stack $(8 \mathrm{~cm})$ by $(13.6 \pm 0.1)^{\circ} \mathrm{C}$, and the stack metal mesh of $(6.1 \pm 0.1)^{\circ} \mathrm{C}$. Even using a travelling wave system, the temperature reduction can reach $21.5^{\circ} \mathrm{C}$ (from $26.5^{\circ} \mathrm{C}$ to $5.1^{\circ} \mathrm{C}$ ). Thus a thermoacoustic cooler has been realized using a stack of luffa, dacron and metal mesh as well as an additional heat exchanger flowing water in order to improve system performance.

Keywords: thermoacoustic; standing wave; organic matter; synthesis; metal.

\section{PENDAHULUAN}

Penelitian yang dilaporkan ini merupakan kesinambungan, inovasi dan pengembangan dari penelitian-penelitian sebelumnya yang telah dilakukan oleh pengusul dan kawan-kawan $[1,2,3]$. Pada penelitian terdahulu, pengusul dan kawan kawan telah

\footnotetext{
${ }^{*}$ Correspondence: agungbambang@ugm.ac.id Departemen Fisika, Fakultas Matematika dan Ilmu Pengetahuan Alam, Universitas Gadjah Mada, Yogyakarta, Indonesia Full list of author information is available at the end of the article ${ }^{\dagger}$ Equal contributor
}

membangun sebuah sistem pendingin termoakustik menggunakan resonator silindris. Dalam hal ini telah diselidiki pengaruh variasi parameternya yaitu variasi frekuensi [4], variasi posisi stack dalam silinder resonator [5], variasi diameter resonator [6], dan variasi amplitudo bunyi [7] terhadap kinerja sistem pendingin tersebut. Kemudian, penyelidikan pengaruh amplitudo (intensitas) dan frekuensi bunyi yang digunakan terhadap kinerjanya, diperoleh hasil bahwa penurunan suhu terbesar terjadi pada frekuensi resonansi sistem resonator dan sebanding 
dengan intensitas bunyi yang digunakan $[1,4,5,7]$. Penelitian terus berlanjut, dilakukan penelitian untuk mempelajari pengaruh geometri resonator silindris yang digunakan, meliputi panjang dan diameternya, terhadap kinerja piranti pendingin yang telah dibuat hingga diperolehnya diameter optimum yaitu memberikan pendinginan maksimum $[3,2,6]$. Di samping itu juga telah diteliti pengaruh kinerja sistem menggunakan stack berpori acak berbahan logam [8].

Di samping itu juga telah diteliti pengaruh kinerja sistem menggunakan stack berpori acak berbahan logam maupun non-logam/organik $[9,10$, 11]. Dengan banyaknya parameter yang menentukan kinerja pendingin termoakustik, maka pada penelitian ini dibatasi yaitu pengaruh perubahan suhu dengan penggunaan stack bahan alami (gambas), sintetis (dacron) dan mesh logam serta adanya penukar kalor tambahan yang dialiri air.

Dari uraian di atas, maka tujuan khusus dari penelitian ini adalah meneliti pengaruh kinerja termoakustik dengan adanya stack bahan alami (gambas), sintetis (dacron) dan mesh logam serta penukar kalor tambahan terisi cairan yang mengalir dalam resonator.

Meskipun pada dasarnya masih banyak parameter yang menentukan kinerja dan efisiensi pendingin termoakustik, antara lain jenis dan tekanan gas, bahan stack, kinerja loudspeaker, konfigurasi resonator, dan lain-lain $[12,13,14,15,16,17]$. Dengan adanya penelitian yang bertahap dan berkesinambungan, diharapkan pada akhir tujuan jangka panjang yang ingin diperoleh adalah terwujudnya piranti pendingin termoakustik yang memiliki efisiensi tinggi sehingga layak diproduksi secara komersial dan masal.

Secara umum, telah dipaparkan dalam Latar Belakang, urgensi penelitian ini terletak pada terbentuknya alat pendingin yang ramah lingkungan karena menggunakan udara (alat pendingin non-freon). Selain sifatnya yang ramah lingkungan karena menggunakan zat pendingin yang melimpah dan tak habis (inexhaustible), seperti udara atau gas mulia, pendingin termoakustik ini menggunakan gelombang bunyi dalam proses pendinginan.

Secara khusus, pentingnya penelitian ini adalah terletak pada kinerja stack bahan alami (gambas), sintetis (dacron) dan mesh logam serta penukar kalor tambahan bercairan dalam proses transfer kalor untuk memperoleh pendinginan yang lebih baik atau dengan kata lain diharapkan kinerja sistem meningkat. Adapun gambas, dacron atau mesh logam dipilih dikarenakan bahan tersebut adalah salah satu bentuk stack yang berpori acak dan terbuat dari bahan alami, sintetis dan logam sehingga mudah diperoleh di pasaran dan murah harganya.

\section{METODE PENELITIAN}

Seperti telah disebutkan di Latar Belakang bahwa penelitian ini merupakan kelanjutan dari penelitian-penelitian sebelumnya secara bertahap dan berkesinambungan. Dalam penelitian ini, dimulai dengan tahap pengadaan stack bentuk pori acak bahan organik (gambas kering), bahan sintesis (dakron) dan bahan logam (mesh) (Gambar 1).

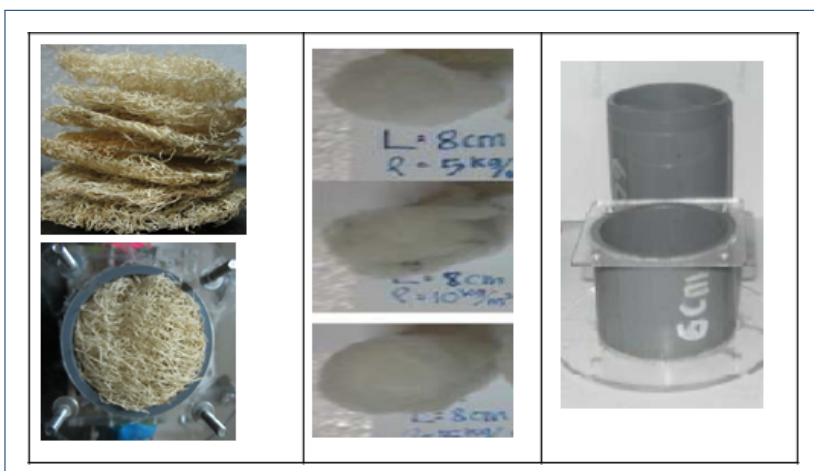

Gambar 1: Penampang bahan stack gambas, dakron dan mesh logam [18, 19, 8].

Pada Tahap Pelaksanaan, yaitu penyusunan piranti pendingin termoakustik dan sistem pengukurannya, menggunakan stack gambas, dakron atau mesh logam termasuk penukar kalor tambahan yang tersusun seperti Gambar 2. Susunan sistem (Gambar 2) terdiri dari resonator pipa PVC bentuk silindris yang di dalamnya terdapat sebuah stack (gambas, dakron atau mesh logam) yang berfungsi sebagai penukar kalor utama dan yang membentuk ruang di sebelah kanan stack merupakan reservoir kanan (tandon dingin) dan di sebelah kiri stack merupakan reservoir kiri (tandon panas). Suhu kedua reservoir diukur masing-masing dengan menggunakan termometer digital.

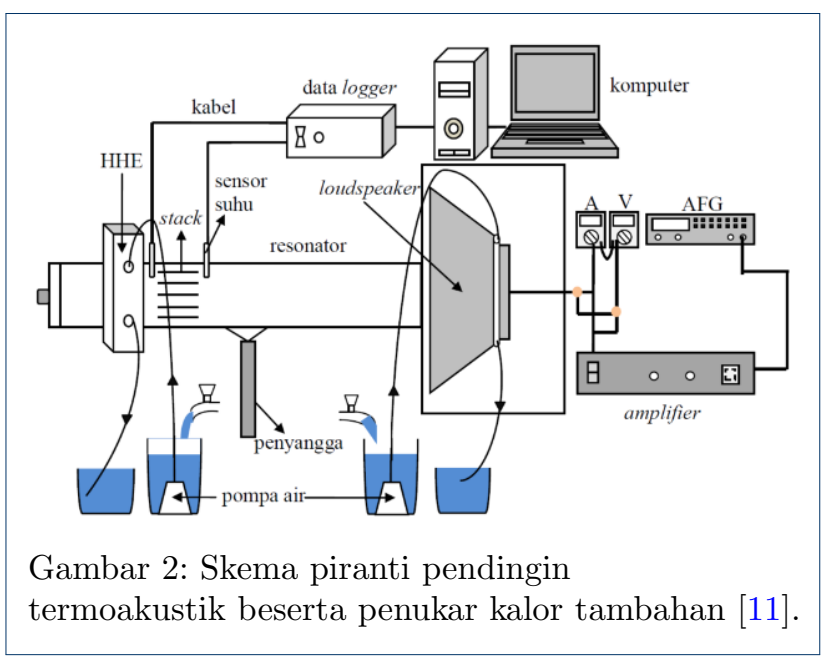


Dalam hal ini dapat teramati seberapa besar perubahan suhu tandon dan seberapa besar beda suhu antara tandon dingin - tandon panas.

Eksperimen selanjutnya dilakukan dengan memasang penukar kalor tambahan pada tandon panas (dekat stack bagian kiri). Dalam hal ini akan diamati seberapa besar perubahan suhu kedua tandon, sehingga dapat dibandingkan perubahan suhu dengan ada tidaknya penukar kalor tambahan tersebut.

Pada Tahap ketiga (Tahap Analisis Hasil), menunjukkan tahap Kinerja piranti termoakustik ini dapat dilihat dari daya pendinginan yang dimilikinya dan tercermin dari seberapa besar penurunan suhu reservoir dingin yang dapat dicapainya. Oleh karena itu, data hasil eksperimen yang telah diperoleh akan dianalisis dengan metode grafik dalam bentuk grafik suhu yang memperlihatkan suhu pada reservoir dingin dan reservoir panas sebagai fungsi waktu. Dalam hal ini melukiskan proses penurunan suhu udara reservoir dingin (juga kenaikan suhu reservoir panas) dengan berjalannya waktu pengoperasian piranti, meliputi laju penurunan suhu dan seberapa besar penurunan suhu tersebut dicapai.

\section{HASIL DAN PEMBAHASAN}

Penelitian sebelumnya untuk stack gambas telah diteliti oleh Candraresita (2013) [10] dan Putri (2013) [18]. Hasil penelitian Candraresita (2013) [10] menunjukkan bahwa penurunan suhu stack gambas sebesar $(5,3 \pm 0,1)^{\circ} \mathrm{C}$ pada panjang optimum $6 \mathrm{~cm}$ (tegangan 10 volt).

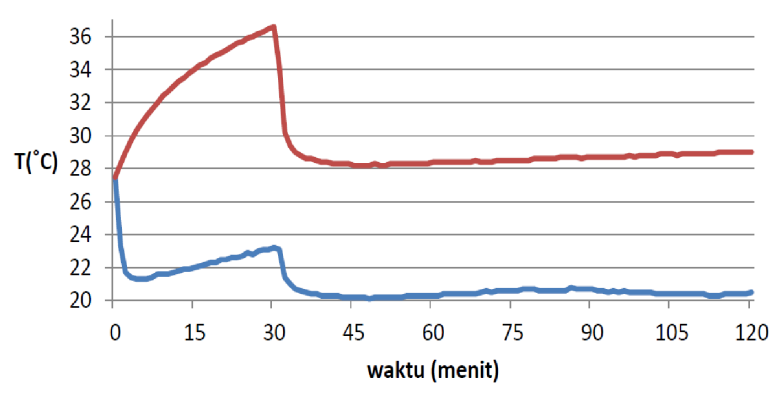

Gambar 3: Grafik penurunan suhu total $(\otimes \mathrm{Tc}$ total) vs waktu (t) pada stack gambas (gelombang berdiri) [18].

Sedangkan penelitian Putri (2013) [18] menunjukkan penurunan suhu maksimum stack gambas $6 \mathrm{~cm}$ sebesar $(7,2 \pm 0,1)^{\circ} \mathrm{C}$ dengan menggunakan $\mathrm{CHE}$ yang dipasang $35 \mathrm{~cm}$ dari loudspeaker. Penelitian ini menunjukkan stack gambas $6 \mathrm{~cm}$ menghasilkan penurunan suhu maksimum $(11,3 \pm 0,1)^{\circ} \mathrm{C}$ pada daya $60 \mathrm{~W}$. Hasil tersebut menunjukkan penurunan suhu yang jauh lebih besar dibanding dengan penelitian sebelumnya.

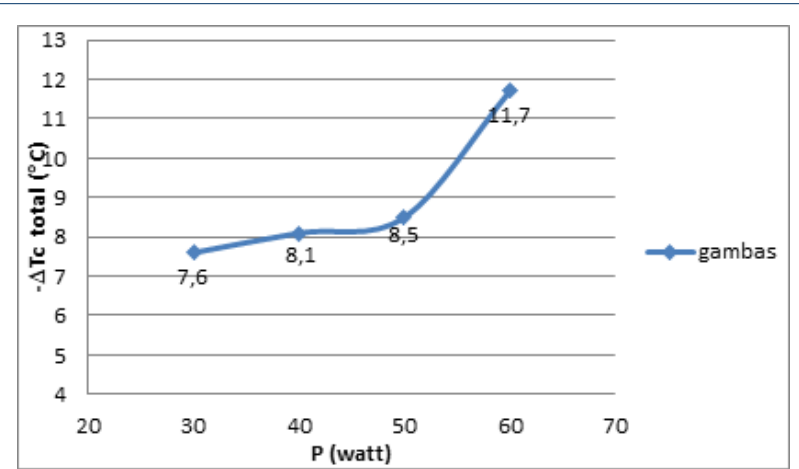

Gambar 4: Grafik penurunan suhu total $(-\Delta \mathrm{Tc}$ total) dan variasi daya loudspeaker pada panjang stack optimum setiap bahan gambas [11].

Hal tersebut dikarenakan penggunaan model penyusunan stack yang berbeda. Model penyusunan stack dalam penelitian ini dengan cara menggulung bahan gambas akan lebih efektif menghasilkan penurunan suhu maksimum dibanding menyusun satu per satu gambas yang berbentuk lingkaran. Secara umum, semakin besar daya loudspeaker yang digunakan, semakin cepat pula pemanasan suhu tandon dingin akibat kalor balik. Selain itu, penggunaan daya yang besar, tegangan yang dibutuhkan juga besar dan tekanan dalam tabung resonator semakin besar sehingga mempengaruhi kecepatan molekul gas. Kecepatan molekul gas mempengaruhi laju transfer kalor dari tandon dingin ke tandon panas. Pada Gambar 3 didapatkan daya loudspeaker optimum, yaitu yang menghasilkan penurunan suhu maksimum pada daya $60 \mathrm{~W}$.

Pada Gambar 4, memperlihatkan kinerja dari stack pori acak bahan sintesis (dakron) bahwasanya stack dakron dengan panjang $8 \mathrm{~cm}$, rapat massa $5 \mathrm{~kg} / \mathrm{m}^{3}$, $10 \mathrm{~kg} / \mathrm{m}^{3}$ dan $15 \mathrm{~kg} / \mathrm{m}^{3}$ menghasilkan penurunan suhu tandon dingin yang lebih besar daripada ukuran panjang yang lain.

Untuk stack dakron dengan panjang $8 \mathrm{~cm}$ dengan rapat massa $5 \mathrm{~kg} / \mathrm{m}^{3}$ dan $10 \mathrm{~kg} / \mathrm{m}^{3}$ menghasilkan penurunan suhu tandon dingin sebesar $(13,6 \pm 0,1)^{\circ} \mathrm{C}$, sedangkan stack $8 \mathrm{~cm}\left(\geqslant 15 \mathrm{~kg} / \mathrm{m}^{3}\right)$ menghasilkan penurunan suhu tandon dingin sebesar $(13,3 \pm 0,1)^{\circ} \mathrm{C}$.

Terlihat suhu tandon dingin turun akibat tandon panas dialiri air melalui penukar kalor. Namun kebanyakan suhu tandon dingin setelah mengalami penurunan tersebut tampak kurang stabil (naik turun). Hal ini disebabkan karena setelah pengoperasian peranti termoakustik dalam jangka 
waktu tertentu, stack mengalami pengembunan sehingga basah.
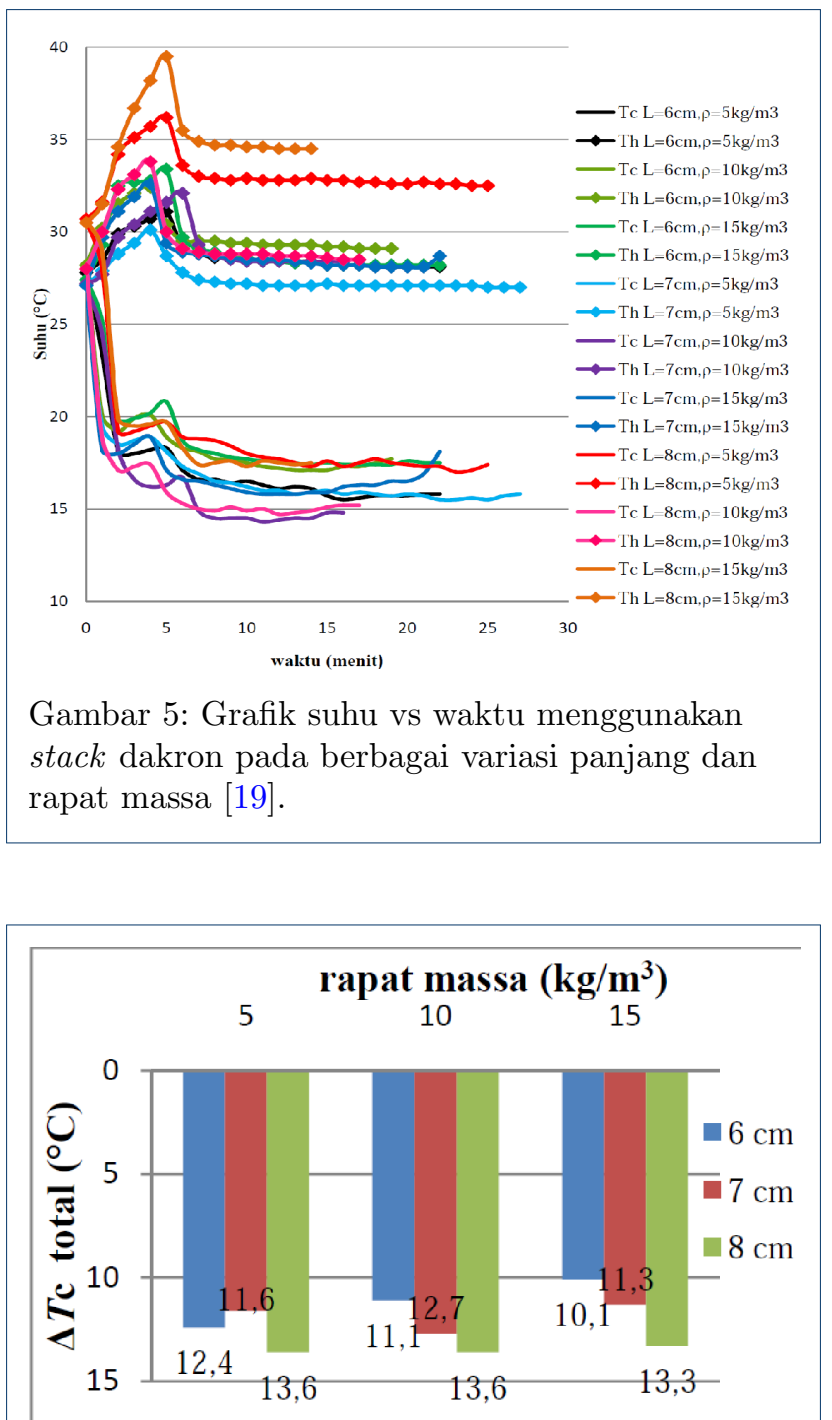

Gambar 6: Pengaruh bahan, panjang dan rapat massa stack dakron terhadap penurunan suhu tandon dingin [19].

Akibatnya gelombang bunyi yang melewati stack mengalami gangguan sehingga juga mengganggu proses pemompaan kalor dari tandon dingin ke tandon panas karena keberadaan air. (Gambar 5)

Pada Gambar 5 bagian dingin (berwarna biru), hot heat exchanger mampu untuk menurunkan suhu kembali. Pada detik pertama hingga detik 1800, hot heat exchanger belum diberikan aliran air, sehingga yang didapatkan adalah suhu yang Gambar 6. Perubahan suhu pada saat peranti termoakustik dengan hot heat exchanger yang dialirkan air menurun namun akan naik kembali karena adanya aliran kalor balik. Ketika proses akan menaik tersebut yaitu pada detik 1800, hot heat exchanger dialiri air, sehingga suhu menjadi turun.

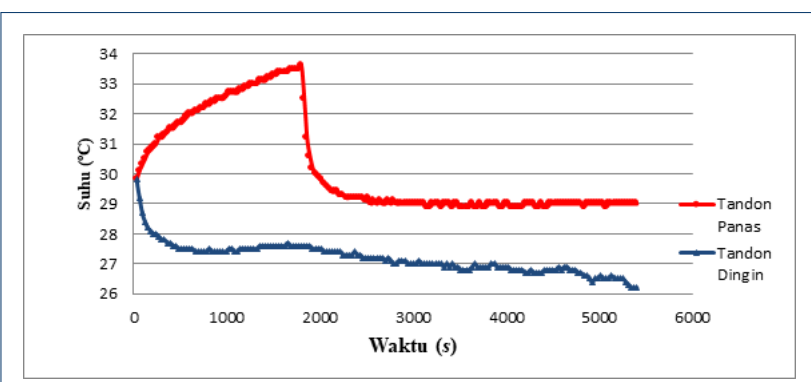

Gambar 7: Grafik suhu vs waktu sistem termoakustik dengan stack mesh logam dan hot heat exchanger [8].

Pada penurunan tersebut hot heat exchanger mampu menunjukkan sifatnya, yaitu menurunkan suhu pada tandon dingin hingga tidak naik lagi, yang semula naik akibat adanya arus kalor balik dari tandon panas. Hal tersebut merupakan bukti bahwa hot heat exchanger mampu memberikan penurunan suhu secara optimal baik dari bagian panas maupun bagian dingin.

Hasil terbaik yang diperoleh dari penelitian ini adalah bahwa transfer kalor terbaik jika menggunakan stack ber mesh 18 dengan panjang $L=5 \mathrm{~cm}$ dan menggunakan frekuensi gelombang bunyi $f=105$ $\mathrm{Hz}$, penurunan suhu sebesar $(6,1 \pm 0,1)^{\circ} \mathrm{C}$ yaitu pada suhu $(26,2 \pm 0,1)^{\circ} \mathrm{C}$.

Di lain pihak menggunakan sistem gelombang berjalan (traveling wave) penurunan suhu yang dapat dicapai sebesar $18,7^{\circ} \mathrm{C}$ (dari suhu ruang sebesar $28^{\circ} \mathrm{C}$ turun menjadi $9,3^{\circ} \mathrm{C}$ [20]. Perbaikan sistem dan optimasi parameter dapat diperoleh suhu yang lebih rendah lagi, yaitu sebesar $21,4^{\circ} \mathrm{C}$ (dari suhu kamar $26,5^{\circ} \mathrm{C}$ turun menjadi $\left.5,1^{\circ} \mathrm{C}\right)[21]$.

\section{KESIMPULAN}

Hasil yang diperoleh adalah bahwa telah terjadi perubahan suhu pada tandon di kiri - kanan stack gambas (bahan alami), dakron (sintetis) atau mesh kasa (logam) yang kemudian disebut tandon panas dan dingin. Adapun penurunan suhu tandon dingin terbesar menggunakan jenis stack gambas $(6 \mathrm{~cm})$ dengan penurunan suhu sebesar $(11,3 \pm 0,1)^{\circ} \mathrm{C}$. Sedangkan menggunakan stack dakron $(8 \mathrm{~cm})$ sebesar $(13,6 \pm 0,1)^{\circ} \mathrm{C}$, dan stack mesh logam sebesar $(6,1 \pm 0,1)^{\circ} \mathrm{C}$. Bahkan menggunakan sistem gelombang berjalan, penurunan suhu dapat mencapai $21,5^{\circ} \mathrm{C}$ (dari $26,5^{\circ} \mathrm{C}$ menjadi $5,1^{\circ} \mathrm{C}$ ). Dengan demikian telah terwujud sebuah pendingin termoakustik menggunakan stack pori acak mesh 
logam serta penukar kalor tambahan yang dialiri air dapat meningkatkan kinerja sistem.

\section{PENULIS}

1 Qonitatul Hidayah

Dari :

(1) Departemen Fisika, Fakultas Matematika dan Ilmu Pengetahuan Alam, Universitas Gadjah Mada

2 Putih Asmara

Dari :

(1) Departemen Fisika, Fakultas Matematika dan Ilmu Pengetahuan Alam, Universitas Gadjah Mada

3 Mega C. Gupita

Dari :

(1) Departemen Fisika, Fakultas Matematika dan Ilmu Pengetahuan Alam, Universitas Gadjah Mada

4 Ikhsan Setiawan

Dari :

(1) Departemen Fisika, Fakultas Matematika dan Ilmu Pengetahuan Alam, Universitas Gadjah Mada

5 Agung Bambang Setio Utomo

Dari :

(1) Departemen Fisika, Fakultas Matematika dan Ilmu Pengetahuan Alam, Universitas Gadjah Mada

Pustaka

1. Setiawan, Ikhsan; Utomo, Agung B S ; W, Andi R ; M G. Rancang Bangun Piranti Termoakustik sebagai Pendingin dan Pemanas Udara secara Simultan. Yogyakarta: FMIPA Universitas Gadjah Mada; 2005

2. Setiawan I, Susilowati S, ME ABSU. Laporan Penelitian Dosen Muda 2006. UGM, Yogyakarta. 2006;

3. Setiawan I, Utomo ABS, Maruto G, Wijaya AR. Rancang bangun piranti termoakustik sebagai pemompa kalor. Sigma. 2007;10(1):25-33.

4. Elyanita MS, Setiawan I, Setio Utomo AB. Pengaruh Peubah frekuensi dan posisi stack bahan kardus terhadap peubah suhu pada sistem termoakustik. Jurnal Fisika Indonesia. 2007;(33).

5. Romdhiah; Setiawan, Ikhsan; Utomo ABS. Pengaruh Variasi Posisi Stack dan Frekuensi Gelombang Bunyi Terhadap Perbedaan Suhu pada Sistem Termoakustik dengan Bahan Stack Film. Jurnal Fisika Indonesia. 2006; X(31).

6. Sampurna D, Setiawan I, Setio Utomo AB. Studi eksperimen untuk mengetahui pengaruh diameter tabung resonator silindris terhadap kinerja piranti termoakustik. Jurnal Fisika Indonesia. 2007;(33).

7. Zulheldi IS, Setio Utomo AB. Pengaruh Intensitas Bunyi, Jarak Letak Stack dan Diameter Tabung Resonator pada Piranti Termoakustik. Jurnal Fisika Indonesia. 2006;(31).

8. Achmadin WN. Studi eksperimen untuk mengetahui pengaruh ukuran porositas dan panjang bahan stack serta keberadaan hot heat exchanger terhadap kinerja pendingin termoakustik. Universitas Gadjah Mada; 2012
9. Farikhah I, Ristanto S, Idrus H, Kaltsum U, Faisal A, Setiawan I, et al Thermoacoustic design using stem of goose down stack. In: AIP Conference Proceedings. vol. 1474. American Institute of Physics; 2012. p. 283-286.

10. Candraresita AF. Pengaruh Frekuensi Resonansi dan Panjang Stack pada Kinerja Pendingin Termoakustik Menggunakan Stack Berpori Acak Bahan Organik (Gambas). Yogyakarta: FMIPA Universitas Gadjah Mada; 2013

11. Hidayah Q. Pengaruh Stack berbahan Organik terhadap Perubahan Suhu pada Sistem Pendingin Termoakustik Gelombang Berdiri dan Gelombang Berjalan. Yogyakarta: FMIPA Universitas Gadjah Mada; 2015.

12. Swift GW. Thermoacoustic engines. The Journal of the Acoustical Society of America. 1988;84(4):1145-1180.

13. Swift GW. Thermoacoustics: A unifying perspective for some engines and refrigerators. Acoustical society of America; 2003.

14. Russell DA, Weibull P. Tabletop thermoacoustic refrigerator for demonstrations. American Journal of Physics. 2002;70(12):1231-1233.

15. Zoontjens L, Howard CQ, Zander AC, Cazzolato BS. Development of a low-cost loudspeaker-driven thermoacoustic refrigerator. In: Proceedings of ACOUSTICS; 2005. p. 9-11.

16. Tu Q, Gusev V, Bruneau M, Zhang C, Zhao L, Guo F. Experimental and theoretical investigation on frequency characteristic of loudspeaker-driven thermoacoustic refrigerator. Cryogenics. 2005;45(12):739-746.

17. Setiawan, Ikhsan; Mitrayana; Utomo ABS. Pengembangan Pendingin termoakustik Ramah Lingkungan Menggunakan Dua Buah Stack. In: Proccedings 7th Basic Science National Seminar. Malang: Universitas Brawijaya Malang; 2010.

18. Putri EKN. Studi Pengaruh Penukar Panas untuk Tandon Dingin dan Panas Terhadap Kinerja Sistem Pendingin Termoakustik Menggunakan Stack Berbahan Gambas (Luffa Acutangula). Yogyakarta: FMIPA Universitas Gadjah Mada; 2013

19. Asmara P. Kinerja Piranti Pendingin Termoakustik Gelombang Berdiri dan Gelombang Berjalan Menggunakan Stack Pori Acak. Yogyakarta: FMIPA Universitas Gadjah Mada; 2015.

20. Setiawan I, Fadly MNM, Utomo ABS. Experimental demonstration of the dependence of temperature decrease on the hydraulic radius of regenerator in a traveling-wave thermoacoustic refrigerator. In: Journal of Physics: Conference Series. vol. 820. IOP Publishing; 2017. p. 12012

21. Gupita MC, Setiawan I, Utomo ABS. Studi Eksperimental Pengaruh Frekuensi Bunyi dan Panjang Resonator Lurus Terhadap Penurunan Suhu Dalam Alat Pendingin Termoakustik Tipe Gelombang Berjalan. In: Prosiding SNFA (Seminar Nasional Fisika dan Aplikasinya). vol. 2; p. $128-136$. 